\title{
COMPLICATIONS OF TRACHEAL SLEEVE PNEUMONECTOMY: PERSONAL EXPERIENCE AND OVERVIEW OF THE LITERATURE
}

Giancarlo Roviaro, MD, FACS

Federico Varoli, MD

Alberto Romanelli, MD

Contardo Vergani, MD

Marco Maciocco, MD
Objectives: Tracheal sleeve pneumonectomy, although technically demanding, is considered the choice for tracheobronchial angle cancers. Complications in our 49 tracheal sleeve pneumonectomies are reviewed. Results, complications, and technical aspects are critically discussed. Although series in the literature differ in selection of patients and surgical techniques and extend over long periods, we attempt to compare our experience with results from the literature.

Methods: From 1983 to September 1999, 60 patients eligible for tracheal sleeve pneumonectomy after conventional staging underwent operation. A Sybilla Fome-Cuf ventilation tube (Bivona, Inc, Gary, Ind) was used starting in 1987 to facilitate anastomosis. Since 1993, all patients have undergone video-assisted thoracoscopy immediately before the operation.

Results: There were 11 (18.3\%) exploratory thoracotomies, 48 right tracheal sleeve pneumonectomies, and 1 left tracheal sleeve pneumonectomy. Among the tracheal sleeve pneumonectomies, we recorded $4(8.2 \%)$ perioperative deaths (myocardial infarction, $\mathrm{n}=1$; heart failure, $\mathrm{n}=1$; pulmonary edema, $\mathrm{n}=1$; gastric ulcer hemorrhage, $\mathrm{n}=1$; and anastomotic fistula in a patient who received high-dose radiation before the operation, $n=1)$. We observed $5(10.2 \%)$ complications (lung edema, $\mathrm{n}=1$; transitory recurrent nerve palsy, $\mathrm{n}=2$; empyema without fistula cured conservatively, $\mathrm{n}=1$; and pneumonia, $\mathrm{n}=1)$. Anastomotic stenosis did not occur. Twenty-six $(53 \%)$ patients are alive 14 to 87 months postoperatively, $12(24.5 \%)$ of these more than 5 years postoperatively. Five $(10.2 \%)$ died of mediastinal recurrence at 6 and 54 months. Two others $(4.1 \%)$ died in road accidents.

Conclusions: Tracheal sleeve pneumonectomy is a demanding operation with a high risk of complications. Analysis of literature and personal experience shows that complications can be greatly reduced through accurate selection of patients, precise technique, and optimal postoperative care. Long-term survival equals that obtained after standard pneumonectomy. (J Thorac Cardiovasc Surg 2001;121:234-40)
Q urgical excision is regarded as the treatment of choice for lung cancer; however, radical surgical treatment in the case of locally advanced lung cancer is

From the Department of General Surgery, San Giuseppe Hospital FbF, Milan, Italy.

Received for publication April 10, 2000; revisions requested May 18, 2000; revisions received Sept 18, 2000; accepted for publication Sept 21, 2000.

Address for reprints: Giancarlo Roviaro, MD, Head, Department of General Surgery, San Giuseppe Hospital FbF, Via San Vittore, 12, 20122 Milan, Italy.

Copyright (C) 2001 by The American Association for Thoracic Surgery

$0022-5223 / 2001 \$ 35.00+0 \quad \mathbf{1 2 / 1 / 1 1 1 9 7 0}$

doi:10.1067/mtc.2001.111970 still debated. Cancers originating less than $2 \mathrm{~cm}$ from the carina or at the tracheobronchial angle offer an even greater challenge.

To overcome the difficulty in resecting this kind of tumor, Gibbon ${ }^{1}$ in 1959 devised a personal technique and presented his first cases of tracheal sleeve pneumonectomies. A few other sporadic attempts by other surgeons using different modified techniques were reported in literature during the following years. In 1972 Jensik and coworkers ${ }^{2}$ presented the first consistent series of 17 patients subjected to this technique; in 1982 the same authors ${ }^{3}$ updated the series to 34 patients, with a perioperative mortality of $29 \%$. Other authors subsequently reported limited personal 
experiences with a perioperative mortality reaching $31 \% \cdot{ }^{4-6}$ However, the series were not easily comparable because they extended over long periods, with differing patient selections and surgical techniques.

In the January 1994 issue of this Journal, we ${ }^{7}$ reported a series of 28 tracheal sleeve pneumonectomies that aroused much interest because of the very low mortality and the absence of anastomotic complications. We had in fact recorded only 1 death from myocardial infarction on the thirtieth postoperative day and no cases of stenosis or dehiscence. We received many questions regarding specific technical details such as the tracheobronchial anastomosis, anesthesia, and the preoperative and postoperative management of our patients. Since then we have recorded 3 more deaths, which brought our total perioperative mortality to $8.2 \%$, and other postoperative complications. This encouraged us to carry out an accurate revision of literature. We have therefore considered all series presented in the literature since $1985^{8-17}$ having been carried out by the same surgical team or by similar operative techniques. Results were compared with our series of 49 tracheal sleeve pneumonectomies that were accomplished over a 16-year period. Even considering these criteria, an accurate evaluation of the complications specifically pertinent to tracheal sleeve pneumonectomies as compared with global tracheobronchial resections was sometimes difficult.

\section{Patients and methods}

From 1983 to September 1999, we treated 89 patients who had lung cancer arising less than $2 \mathrm{~cm}$ from the carina or infiltrating the tracheobronchial angle and who therefore were candidates for a tracheal sleeve pneumonectomy. All patients were subjected to routine preoperative staging: total body computed tomography, bone scintigraphy, bronchoscopy, and pulmonary function tests. Mediastinoscopy is not routinely performed for all patients with lung cancer.

Since 1993, all patients with lung cancer at any stage that is deemed operable are subjected to thoracoscopy as the first step of the operation, before thoracotomy, to reveal causes of inoperability undetected by common staging procedures. ${ }^{18}$ The same strategy is applied also for candidates for tracheal sleeve pneumonectomy.

Of 89 patients, $29(32.5 \%)$ were considered to have inoperable disease after conventional preoperative staging, specifically because of extracapsular subcarinal mediastinal lymphadenopathy in $13(14.6 \%)$ cases, evident mediastinal invasion in $8(8.9 \%)$ cases, and distant metastases in $8(8.9 \%)$ cases.

Sixty $(67.4 \%)$ patients were judged to have operable disease on the basis of conventional preoperative staging and underwent operation. In $6(10 \%$ of all surgically treated patients) who had been referred to us before 1993 (and who therefore had not undergone video-assisted thoracoscopy), thoracotomy showed involvement of the venae cavae in 3 patients and pleural carcinosis without effusion in the 3 other patients.

Among 5 (8.3\%) patients who had undergone operation after 1993, video-assisted thoracoscopy in 2 patients showed unsuspected pleural carcinosis without pleural effusion, thus avoiding a useless exploratory thoracotomy. In the other 3 patients, video-assisted thoracoscopy could not be completed because of diffuse adhesions, and thoracotomy showed the inoperability of the lesion as a result of caval invasion in 2 patients and involvement of the pulmonary artery below the vena cava in 1 patient. Therefore, 11 (18.3\%) exploratory operations were carried out because preoperative staging had failed to show any evidence of inoperability.

Of the remaining patients, 48 had a right and 1 a left tracheal sleeve pneumonectomy. All operations were performed through a posterolateral thoracotomy in the fifth intercostal space, because this approach is technically simpler and ensures a more complete exposure of the carina and the entire trachea than does sternotomy.

Fifteen patients also required intrapericardial dissection and ligature of the pulmonary vessels. In no case was the anastomosis covered with viable pedicled tissue.

Histologic examination of the specimens revealed 32 $(65.3 \%)$ squamous cell carcinomas, $11(22.5 \%)$ adenocarcinomas, $3(6.1 \%)$ large cell carcinomas, $2(4.1 \%)$ adenoid cystic carcinomas, and $1(2 \%)$ rare blastoma. If this last case of blastoma is excluded, the cases were classified as 22 pT3 N0, 13 pT3 N1, and 12 pT3 N2 according to the American Joint Committee on TNM staging. In 1 patient who had undergone neoadjuvant chemotherapy for epidermoid carcinoma, histologic examination could reveal no residual tumor ("complete pathologic response"). Clinical TNM stage had been T3 N0 in 34 cases and T3 N2 in 14 cases.

Of the 49 patients subjected to tracheal sleeve pneumonectomy, $27(55.1 \%)$ did not receive preoperative neoadjuvant treatment, $17(34.6 \%)$ received low-dose (30 Gy) radiotherapy according to the Paulson protocol, ${ }^{5} 2(4.1 \%)$ patients received high-dose (60 Gy) radiotherapy, $2(4.1 \%)$ patients underwent chemotherapy, and $1(2.1 \%)$ patient underwent both chemotherapy and low-dose (30 Gy) radiotherapy.

Surgical technique. Our surgical technique has already been thoroughly discussed in a previous work ${ }^{7}$; we will therefore merely outline the main points. Ventilation techniques altered over time until 1987, when the present technique was established. Since 1987 we have used the Sybilla Fome-Cuf tube produced by Bivona, Inc (Gary, Ind), for ventilation, which greatly facilitates all maneuvers. This is a slender, silicone-reinforced tube, 5 to $6.5 \mathrm{~mm}$ in diameter and $45 \mathrm{~cm}$ in length, with a small, self-inflating polyurethane foam cuff located $1.5 \mathrm{~cm}$ from the tip. General anesthesia is induced and the patient is intubated with a double-lumen Carlens tube. Once the thoracic cavity is open, the distal trachea and carina are mobilized. Two traction threads are placed around the trachea and left main bronchus; the anterior aspect of the trachea is then delicately isolated for a distance of 4 to $5 \mathrm{~cm}$. 
Table I. Personal experience with complications after 49 tracheal sleeve pneumonectomies (48 right and 1 left tracheal sleeve pneumonectomies)

\begin{tabular}{llr}
\hline & No. of cases & Rate \\
\hline Periop mortality & 4 & $8.2 \%$ \\
Global incidence of complications & 9 & $18.3 \%$ \\
Early respiratory failure & 2 (1 periop death) & $4.1 \%$ \\
Cardiac events & 2 (2 periop deaths) & $4.1 \%$ \\
Bronchopleural fistula & 1 (1 periop death) & $2 \%$ \\
Digestive tract bleeding & 1 . & $2 \%$ \\
Empyema & 1 & $2 \%$ \\
Contralateral pneumonia & 1 & $4.1 \%$ \\
Recurrent nerve paralysis & 2 & \\
\hline
\end{tabular}

At this point the left main bronchus is severed at the second bronchial ring, intubated, and transiently ventilated from the operative field with a 6-mm Portex tube (Concord/Portex, Keene, NH). Pneumonectomy and resection of the carina are then carried out, and a stiff lead is inserted through the Carlens tube from the operative field. The anesthetist can then withdraw the Carlens tube and replace it with a Sybilla tube, which can then easily be positioned in the left main bronchus by the surgeon. The anastomosis is then created by placing interrupted stitches knotted on the outer side of the bronchus with a 3-0 polyglactin-intertwined thread (Vicryl; Ethicon, Inc, Somerville, NJ). The stitches are positioned about $2 \mathrm{~mm}$ apart on the bronchus and about $3 \mathrm{~mm}$ apart on the trachea, starting from the deeper ones. Once the suture has been completed, the ventilation tube is withdrawn above the anastomosis and a hydropneumatic test is carried out. No further maneuvers for mobilizing the hilum are necessary, and we do not cover the anastomosis with viable tissue. Lymphadenectomy of carinal, paracaval, and paratracheal lymph nodes is accurately performed routinely. The patient is usually extubated in the operating room after bronchoscopic evaluation of the anastomosis and vocal chord mobility. The mean operative time is 160 minutes. During the anastomosis, single-lung ventilation pressure ranges between 20 and 25 $\mathrm{mm} \mathrm{Hg}$ with an oxygen tension of $80 \%$. Tidal volume ranges between 550 and $650 \mathrm{~mL}$ with a mean rate regulated according to the arterial oxygen saturation and carbon dioxide tension. During the operation $1500 \mathrm{~mL}$ of fluid is administered. Halfway through the procedure, $1.5 \mathrm{mg}$ of betamethasone and $20 \mathrm{mg}$ of furosemide are administered (the latter regardless of blood pressure alterations). Both doses can be repeated at the end of the operation.

During the postoperative course, the patient's cervical spine is kept in the normal position without flexing the neck.

\section{Results}

No intraoperative deaths occurred, although there were 4 perioperative deaths $(8.2 \%)$ (Table I). One patient died of myocardial infarction on the twenty-second postoperative day, and another patient died of heart failure due to dilated cardiomyopathy on the eighth postoperative day. The 2 other patients had both been subjected to high-dose (60 Gy) radiotherapy and died of noncardiogenic pulmonary edema on the second postoperative day and of gastric ulcer hemorrhage on the twenty-second postoperative day, respectively. In this last case, clinical and radiologic signs of bronchial fistula had appeared on the ninth postoperative day, and bronchoscopy had shown a small fistula on the right edge of the anastomosis, but no sign of respiratory distress had been present.

Major perioperative complications were encountered in 5 (10.2\%) other patients. One patient had a noncardiogenic lung edema that resolved after tracheotomy and assisted ventilation for 3 months. Dysphonia resulting from transient paresis of the recurrent nerve after extended mediastinal lymphadenectomy was experienced by 2 patients and resolved within 4 months. One patient had an empyema 1 month postoperatively, but there was no evidence of bronchopleural fistula and the empyema resolved with conservative treatment. One last patient had pneumonia that resolved with antibiotic treatment.

Minor and unspecific complications that did not require treatment are not described. We have not encountered any instances of late stenosis of the anastomosis.

At follow-up, 26 patients (53\%) are alive and free of disease 14 to 87 months postoperatively, $12(24.5 \%)$ of these more than 5 years postoperatively. Five $(10.2 \%)$ patients died of mediastinal recurrence and $16(32.7 \%)$ of distant metastases between 6 and 54 months after the operation. Two $(4.1 \%)$ other patients died of unrelated causes-traffic accidents-13 and 42 months postoperatively.

\section{Discussion}

Tracheal sleeve pneumonectomy is an aggressive procedure for resecting bronchial carcinomas involving the tracheobronchial angle, carina, or lower trachea. We now perform tracheal sleeve pneumonectomy in all non-small cell lung cancers invading the main bronchus that are less than $2 \mathrm{~cm}$ distal to the carina or that arise at the tracheobronchial angle and extend along no more than 3 cartilaginous rings on the distal tracheal wall.

The operation is almost exclusively performed on the right side because tumors on the left side rarely meet the correct criteria for tracheal sleeve pneumonectomy. As a matter of fact, tumors of the left main stem bronchus almost always invade the structures of the subaortic space. Furthermore, left tracheal sleeve pneumonectomy is a much more complicated and demanding procedure with a greater occurrence of postoperative complications. Indications for left tracheal sleeve pneumonectomy remain exceptional and limited to young patients with a low degree of malignancy who therefore have a good chance of survival. Reports of left tracheal sleeve pneumonectomy in the literature are rare in comparison with the total number of tracheal sleeve pneumonectomies. ${ }^{19,20}$ 
Table II

\begin{tabular}{|c|c|c|c|}
\hline First author & Operative mortality & No. of deaths/cause of death & Rate \\
\hline Deslauriers $^{12}$ (1989) & $29 \%(11 / 38)$ & $\begin{array}{l}\text { 6: Early respiratory failure } \\
\text { 5: Not specified }\end{array}$ & $54.5 \%(6 / 11)$ \\
\hline $\begin{array}{l}\text { Tsuchiya }{ }^{16}(1990): 15 \text { TSPs } \\
\text { out of } 20 \text { resections of carina }\end{array}$ & $15 \%(3 / 20)$ & $\begin{array}{l}\text { 1: Pneumonia } \\
\text { 1: Mallory-Weiss tear } \\
\text { 1: Unknown }\end{array}$ & $\begin{array}{l}33.3 \%(1 / 3) \\
33.3 \%(1 / 3)\end{array}$ \\
\hline Watanabe ${ }^{17}(1990)$ & $17 \%(2 / 12)$ & $\begin{array}{l}\text { 1: Dehiscence of anastomosis } \\
\text { 1: Stroke }\end{array}$ & $\begin{array}{l}50 \%(1 / 2) \\
50 \%(1 / 2)\end{array}$ \\
\hline $\begin{array}{l}\text { Mathisen }^{14} \text { (1991): } 21 \text { TSPs and } \\
2 \text { carina plus pneumonectomy } \\
\text { stump resections out of } 37 \\
\text { resections of carina }\end{array}$ & $8 \%(3 / 37)$ & $\begin{array}{l}\text { 3: Early respiratory failure } \\
\text { (all during TSP) }\end{array}$ & $100 \%(3 / 3)$ \\
\hline Dartevelle $^{9}$ (1995) & $7.2 \%(4 / 55)$ & $\begin{array}{l}\text { 2: Bronchopleural fistula } \\
\text { 2: Early respiratory failure }\end{array}$ & $\begin{array}{l}50 \%(2 / 4) \\
50 \%(2 / 4)\end{array}$ \\
\hline Roviaro (2000) & $8.2 \%(4 / 49)$ & $\begin{array}{l}\text { 1: Early respiratory failure } \\
\text { 1: Digestive tract bleeding with } \\
\text { bronchopleural fistula } \\
\text { 2: Cardiologic }\end{array}$ & $\begin{array}{l}25 \%(1 / 4) \\
25 \%(1 / 4) \\
50 \%(2 / 4)\end{array}$ \\
\hline
\end{tabular}

TSP, Tracheal sleeve pneumonectomy.

In very selected patients who cannot tolerate a tracheal sleeve pneumonectomy, alternative procedures such as tracheal sleeve lobectomy and reimplantation of the intermediate bronchus on the left main stem bronchus can be considered but imply a great number of vascular and anastomotic complications.

In our opinion, the presence of intracapsular mediastinal N2 lymphadenopathy does not represent a contraindication, just as it does not for conventional pneumonectomy. ${ }^{21,22}$ For this reason we do not perform routine mediastinoscopy. Mediastinoscopy is performed only when $\mathrm{N} 3$ disease is suspected. When N2 disease is preoperatively documented, induction therapy is administered.

Since 1993, we have routinely performed exploratory video-assisted thoracoscopy as the very first step of the planned operation.

The consequences regarding respiratory function do not differ from those associated with a standard pneumonectomy. The operation is characterized by the reconstruction phase, during which the lower trachea is anastomosed to the remaining main stem bronchus. The technique has been refined progressively, and the whole procedure can now be considered well defined and standard. Like most authors, ${ }^{10,14,17}$ we use thin, absorbable interrupted stitches for the tracheobronchial anastomosis (3-0 Vicryl thread). A few authors ${ }^{14,16,17}$ protect the anastomosis with a pleural or pericardial flap, but we have never used this technique. Even though minor technical details can vary, placing a correct suture with the most meticulous surgical precision is of paramount importance in limiting subsequent complications at the anastomosis and ensuring a lasting outcome.

The most recent series (later than 1985) ${ }^{8-14,16,17}$ do not record any operative mortality during tracheal sleeve pneumonectomy operations. The perioperative mortality ranges between $10 \%$ and $29 \%$; however, the time span considered is 1 or 2 months postoperatively according to different authors and is therefore very inhomogeneous (Table II).

These data do not differ from those reported in the literature for conventional pneumonectomy. After a conventional pneumonectomy for lung carcinoma, the perioperative rates considered on a 30 day-basis range between $5 \%$ to $15 \%$ but can be as high as $30 \%$ for patients 70 years of age or older. ${ }^{23,24}$ The recent review of the literature by Klemperer and Ginsberg ${ }^{23}$ quoted data from Romano and Mark, ${ }^{25}$ who reported mortality ranging between $0 \%$ and $25 \%$.

A review of the literature (Tables II and III) indicates the main causes of perioperative mortality to be noncardiogenic pulmonary edema with ensuing acute respiratory failure (variously defined as acute respiratory distress syndrome, early respiratory failure, and noncardiogenic pulmonary edema) and complications deriving from the anastomosis. Other infrequent complications such as contralateral pneumonia, cardiovas- 


\section{Table III}

\begin{tabular}{|c|c|c|}
\hline First author & No. of patients/nonlethal complications & Rate \\
\hline \multicolumn{3}{|c|}{ Tsuchiya $^{16}$ (1990): 15 TSPs out of 20} \\
\hline \multirow[t]{5}{*}{ resections of carina } & 3: Abnormal swallowing & $15 \%(3 / 20)$ \\
\hline & 2: Bronchopulmonary fistula & $10 \%(2 / 20)$ \\
\hline & 1: Candida tracheitis & $5 \%(1 / 20)$ \\
\hline & 1: Stenosis & $5 \%(1 / 20)$ \\
\hline & 1: Bronchial rupture during operation & $5 \%(1 / 20)$ \\
\hline \multirow[t]{2}{*}{ Watanabe $^{17}(1990)$} & 1: Dehiscence of anastomosis & $8.3 \%(1 / 12)$ \\
\hline & 1: Aspiration pneumonia & $8.3 \%(1 / 12)$ \\
\hline \multicolumn{3}{|c|}{$\begin{array}{l}\text { Mathisen }^{14} \text { (1991): } 21 \text { TSPs and } 2 \text { carina plus } \\
\text { pneumonectomy stump resections out of } 37\end{array}$} \\
\hline \multirow[t]{5}{*}{ resections of carina } & 5: Pneumonia & $13.5 \%(5 / 37)$ \\
\hline & 9: Atrial fibrillation & $24.3 \%(9 / 37)$ \\
\hline & 4: Anastomotic stenosis & $10.8 \%(4 / 37)$ \\
\hline & 3: Anastomotic separation & $8.1 \%(3 / 37)$ \\
\hline & 3: Left vocal cord dysfunction & $8.1 \%(3 / 37)$ \\
\hline \multirow[t]{3}{*}{ Dartevelle $^{9}$ (1995) } & 1: Bronchopleural fistula & $1.8 \%(1 / 55)$ \\
\hline & 1: Early respiratory failure & $1.8 \%(1 / 55)$ \\
\hline & 4: Hemothorax & $7.2 \%(4 / 55)$ \\
\hline \multirow[t]{4}{*}{ Roviaro (2000) } & 1: Early respiratory failure & $2 \%(1 / 49)$ \\
\hline & 1: Empyema & $2 \%(1 / 49)$ \\
\hline & 1: Contralateral pneumonia & $2 \%(1 / 49)$ \\
\hline & 2: Transitory recurrent nerve paralysis & $4.1 \%(2 / 49)$ \\
\hline
\end{tabular}

cular complications, and digestive tract bleeding are also reported in the literature.

Acute respiratory failure is reported to be as high as $22 \%$ in the literature ${ }^{11}$ and is characterized by a $50 \%$ to $100 \%$ mortality. In our experience, acute respiratory failure occurred in $2(4 \%)$ cases. One patient had uncontrollable bronchorrhea and died on the second postoperative day; the second patient required assisted ventilation for 3 months but recovered. As reported by all the authors and corroborated by our experience, acute respiratory failure normally developed within 24 to 72 hours after the operation, with diffuse interstitial infiltration insidiously making its appearance in the remaining lung. Notwithstanding aggressive treatment with diuretics, antibiotics, corticosteroids, regular bronchoscopic cleansing of the trachea and bronchi, and even assisted ventilation, respiratory failure progressively develops and can lead to death within a few days. At autopsy, intense congestion of the lung with no apparent cause is invariably present. Several authors $^{26,27}$ have suggested that the resection of all afferent and efferent nerve pathways and the damage to the mediastinal lymphatic system after mobilization of the lung during the operation give rise to malfunction of epithelial clearance mechanisms, mediastinal shifting, pulmonary hypertension, and left ventricular failure. Acute respiratory failure is an event that cannot be foreseen at present. However, scrupulous and repeated bronchoscopic cleansing of bronchial secretions is of paramount importance. Even more important is an accurate water and solute balance; the patient's fluid intake must be cautiously limited to a bare minimum during the operation and the immediate postoperative period, such as $1500 \mathrm{~mL}$ during the first day and gradual resumption of food on the second day. Intrathoracic pressure of the pleural cavity of the resected side must be maintained between -2 and $-8 \mathrm{~mm} \mathrm{Hg}$ by thoracentesis. Acute respiratory failure seems not to be attributed to technical surgical mistakes.

Another fearsome complication is pleural empyema, which can occur with or without a bronchopleural fistula. Tracheal sleeve pneumonectomy can be functionally defined as a pneumonectomy characterized by the presence of an anastomosis instead of a suture on the bronchial stump. Despite current prophylaxis regimens and the constant improvement of operative techniques, pleural empyema is reported in the literature to occur at a rate of $1 \%$ to $4 \%{ }^{23,24}$ after pneumonectomy for malignancy and a rate of 5\% to $8 \%$ after tracheal sleeve pneumonectomy. ${ }^{8,15}$ In our experience, empyema occurred in $1(2 \%)$ case and therefore equals the postpneumonectomy rate reported in literature. The persistence of a pleural empyema that has not been immediately and adequately drained determines an extremely high risk of seepage through the bronchial stump or through the suture rim, with ensuing secondary fistulization. 
Volume 121, Number 2

Table IV. Mortality and 5-year survivals after tracheal sleeve pneumonectomy for bronchogenic carcinoma

\begin{tabular}{lccc}
\hline First author (dates) & No. of cases & Operative mortality $(\%)$ & Five-year survival $(\%)$ \\
\hline Deslauriers $^{12}(1989)$ & $38(1968-1987)$ & 29 & 13 \\
Tsuchiya $^{16}(1990)$ & $20(1977-1989)$ & 15 & 59 (at 2 y) \\
Watanabe $^{17}(1990)$ & $12(1975-1990)$ & 17 & Not reported \\
Mathisen $^{14}(1991)$ & $37(1973-1991)$ & 8 & 49 \\
Dartevelle $^{9}(1995)$ & $55(1981-1995)$ & 7.2 & 24.5 \\
Roviaro (2000) & $49(1983-1999)$ & 8.2 & \\
\hline
\end{tabular}

Conversely, a pleural empyema can itself be due to an anastomotic fistula. Factors traditionally considered to be responsible for the development of a fistula in case of pneumonectomy are inflammation or malignant infiltration of the bronchial stump, excessive dissection of the stump that compromises its blood supply, inaccurate suturing techniques, excessive length of the bronchial stump, and preoperative radiotherapy. Fistulization is still considered to be a dreadful complication and is difficult to control. According to the literature, fistulization occurs at a rate of $5 \%$ to $10 \%{ }^{8,24}$ after tracheal sleeve pneumonectomy compared with the slightly lower rate $(1 \%-4 \%)$ reported after conventional pneumonectomy. ${ }^{24}$ The tracheobronchial anastomosis therefore appears to determine a higher risk of fistulization; this could be due to a greater risk of compromising the blood supply determined by tracheal mobilization and dissection maneuvers, even when the classic procedures described by Grillo and associates ${ }^{28,29}$ are followed.

Cardiovascular complications such as myocardial infarction, heart failure, and serious conduction disorders are a further cause of perioperative mortality after tracheal sleeve pneumonectomy; the incidence reported in the literature reaches $19.8 \%$ of cases in some series. ${ }^{15}$ The incidence of cardiovascular complications reported in the literature is equal to that after conventional pneumonectomy. The same is true for pneumonia of the residual lung (15.4\%). ${ }^{15}$ Surprisingly, digestive tract bleeding represented a significant percentage of complications in a number of series, including our own (between $1.8 \%$ and $6.6 \%)^{8,16}$ with a mortality rate of $100 \%$.

Preoperative radiotherapy, particularly high-dose radiotherapy, is considered a major determinant of postoperative complications. According to several authors, ${ }^{8,12}$ preoperative radiotherapy should be avoided because of the higher risk of postoperative complications and mortality. In our experience, no increased incidence of complications was observed in patients who had undergone low-dose (30 Gy) preoperative radiotherapy according to the Paulson protocol ${ }^{5}$ com- pared with patients who had not undergone radiotherapy. However, the 2 patients who had undergone highdose (60 Gy) preoperative radiotherapy had serious complications that led to death in the immediate postoperative period in both instances. The first patient had had a high-dose (60 Gy) treatment. Evaluation after radiotherapy had shown a good result, and the patient had therefore undergone tracheal sleeve pneumonectomy. His postoperative course had been uneventful until the ninth day, when clinical and x-ray evidence of fistulization developed. A small bronchial fistula was found on the right edge of the suture. A tracheostomy was then carried out and the patient was intubated with a Sybilla tube (the same tube we use for carrying out the anastomosis) by inflating the balloon distal to the anastomosis. The pleural cavity was then drained, but during the following days repeated bronchoscopic examinations showed no appearance of granulation tissue or other signs of healing on the anastomosis. The patient died on the twenty-second postoperative day of a fatal hemorrhage from a gastric ulcer.

In the second patient (a 71-year-old man), a highdose (60 Gy) treatment had determined a marked reduction of the tumor mass. Because we were still uncertain about the role of high-dose radiotherapy in facilitating dehiscence of the suture in the previous case, and in consideration of the patient's good general condition, we decided to proceed to a tracheal sleeve pneumonectomy. Severe bronchorrhea developed on the first postoperative day necessitating repeated bronchoscopic cleansing, which always showed a normal appearing tracheobronchial anastomosis. The patient died on the eighth postoperative day of pulmonary edema. Now we strongly recommend that preoperative radiotherapy be limited to $30 \mathrm{~Gy}$.

\section{Conclusions}

Tracheal sleeve pneumonectomy is usually considered a technically extremely demanding operation characterized by a high risk of complications. It is performed in only a few centers worldwide with limited series. However, a review of current literature and our 
experience indicate that this concept must be overcome (Table IV). Surgical and anastomotic techniques, even though complex, are now perfectly defined. In the hands of experienced teams, postoperative morbidity and mortality rate do not differ from those after conventional pneumonectomy. Accurate selection of patients, a meticulous adherence to surgical precision, and optimal postoperative patient care are mandatory to reduce the risk of the most serious complications, such as noncardiogenic pulmonary edema and suture dehiscence. However, these complications are not specific to tracheal sleeve pneumonectomy and do not appear to be directly attributable to inadequacy of surgical or anesthesiology techniques.

The role of neoadjuvant therapy is still debated. However, in our experience, when neoadjuvant therapy is administered at a correct dosage it does not appear to alter the operative course or increase the risk of complications.

At present, tracheal sleeve pneumonectomy is the only concrete treatment for tumors that originate at the tracheobronchial angle and must be considered in every patient who is a candidate. In experienced hands, longterm survival after tracheal sleeve pneumonectomy is equal to survival after pneumonectomy for locally advanced tumors and shares the same prognostic factors. ${ }^{10,17,30}$

\section{REFERENCES}

1. Gibbon JH. Discussion of Chamberlain JM, McNeill TM, Parnassa P, Edsall JR. Bronchogenic carcinoma: an aggressive surgical attitude. J Thorac Cardiovasc Surg 1959;38:727.

2. Jensik RJ, Faber LP, Miloy FY, et al. Tracheal sleeve pneumonectomy for advanced carcinoma of the lung. Surg Gynecol Obstet 1972;134:231-6.

3. Jensik RJ, Faber LP, Kittle CF, et al. Survival in patients undergoing tracheal sleeve pneumonectomy for bronchogenic carcinoma. J Thorac Cardiovasc Surg 1982;84:489-96.

4. Deslauriers J, Beaulieu M, Benazera A, McClish A. Sleeve pneumonectomy for bronchogenic carcinoma. Ann Thorac Surg 1979;28:465-74.

5. Paulson DL, Urschel HC, McNamara JJ, et al. Bronchoplastic procedures for bronchogenic carcinoma. J Thorac Cardiovasc Surg 1970;59:38-48.

6. Pearson FG, Todd TRJ, Cooper JD. Experience with primary neoplasm of the trachea and carina. J Thorac Cardiovasc Surg 1984;88:511-8.

7. Roviaro GC, Varoli F, Rebuffat C, et al. Tracheal sleeve pneumonectomy for bronchogenic carcinoma. J Thorac Cardiovasc Surg 1994;107:13-8.

8. Dartevelle PG, Khalife J, Chapelier A, et al. Tracheal sleeve pneumonectomy for bronchogenic carcinoma: report of 55 cases. Ann Thorac Surg 1988;46:68-72.
9. Dartevelle PG, Macchiarini P, Chapelier A. Tracheal sleeve pneumonectomy. Ann Thorac Surg 1995;60:1854-5.

10. Dartevelle PG, Macchiarini P. Techniques of pneumonectomy: sleeve pneumonectomy. Chest Surg Clin North Am 1999;9, 2:407-17.

11. Deslauriers J. Involvement of the main carina. In: Delarue NC, Eschapasse $\mathrm{H}$, editors: International trends in general thoracic surgery. Vol 1. Philadelphia: WB Saunders; 1985. p. 136.

12. Deslauriers J, Beaulieu M, McClish A. Tracheal sleeve pneumonectomy. In: Shields TW, editor: General thoracic surgery. ed 3. Philadelphia: Lea and Febiger; 1989. p. 382-7.

13. Maeda M, Nakamoto K, Ohta M, et al. Statistical survey of tracheobronchoplasty in Japan. J Thorac Cardiovasc Surg 1989;97:402-14.

14. Mathisen DJ, Grillo HC. Carinal resection for bronchogenic carcinoma. J Thorac Cardiovasc Surg 1991;102:16-23.

15. Tedder M, Anstadt MP, Tedder SD, et al. Current Morbidity, mortality, and survival after bronchoplastic procedures for malignancy. Ann Thorac Surg 1992;54:387-91.

16. Tsuchiya R, Goya T, Naruke T, et al. Resection of tracheal carina for lung cancer. J Thorac Cardiovasc Surg 1990;99:779-87.

17. Watanabe Y, Shimizu J, Oda M, et al. Results in 104 patients undergoing bronchoplastic procedures for bronchial lesions. Ann Thorac Surg 1990;50:607-14.

18. Roviaro GC, Varoli F, Rebuffat C, et al. Videothoracoscopic staging and treatment of lung cancer. Ann Thorac Surg 1995;59:971-4.

19. Gilbert A, Deslauriers J, McClish A, Piraux M. Tracheal sleeve pneumonectomy for carcinomas of the proximal left main bronchus. Can J Surg 1984;27:583-5.

20. Dartevelle PG, Khalife J, Chapelier A, et al. Tracheal sleeve pneumonectomy for bronchogenic carcinoma: report of 55 cases. Ann Thorac Surg 1988;46:68-72.

21. Pezzuoli G, Roviaro GC, Varoli F, et al. Locally advanced lung cancer treatment: personal experience of 588 stage III operated on patients. Helv Chir Acta 1989;56:719-24.

22. Naruke T, Goya T, Tsuchiya R, Suemasu K. The importance of surgery to non-small cell carcinoma of the lung with mediastinal lymph node metastasis. Ann Thorac Surg 1988;46:603-10.

23. Klemperer J, Ginsberg RJ. Morbidity and mortality after pneumonectomy. Chest Surg Clin North Am 1999;3:515-25.

24. Shields TW. General features and complications of pulmonary resections. In Shields TW, editor. General thoracic surgery. ed 4, Vol 2. Philadelphia: Williams \& Wilkins; 1994. p. 391-414.

25. Romano PS, Mark DH. Patient mortality and hospital characteristics related to in hospital mortality after lung resection. Chest 1992;101:1332-7.

26. Shapira OM, Shahian DM. Post pneumonectomy pulmonary edema. Ann Thorac Surg 1993;56:190-5.

27. Zeldin RA, Normandin D, Landtwing D, et al. Postpneumonectomy pulmonary edema. J Thorac Cardiovasc Surg 1984;87:359-65.

28. Grillo H. Carinal resection. Ann Thorac Surg 1982;34:356-73.

29. Grillo H. Carcinoma of the lung: What can be done if the carina is involved? Am J Surg 1982;143:694-6.

30. Faber LP. Results of surgical treatment of stage III lung carcinoma with carinal proximity: the role of sleeve lobectomy versus pneumonectomy. Surg Clin North Am 1987;67:1001-14. 